\title{
Biological Control of Chili Anthracnose Disease with Rhodotorula Spp.
}

\author{
Dian Indratmi \\ Department of Agrotechnology, \\ University of Muhammadiyah Malang \\ Malang, Indonesia \\ indratmidian@yahoo.co.id \\ dian@umm.ac.id
}

\begin{abstract}
This study aims at determining the ability of yeast Rhodotorula sp. to inhibit the infection and anthracnose disease on chili during the test both in the laboratory and on the field. The fructosphere isolation resulted in seven yeast isolates of Rhodotorula sp whose colonies are pink, reddish, coral. On the Rodhotorula the medium of glucose peptone yeast agar extract, well known as GPY medium, the mucoid colony appeared to be soft with a smooth surface. The edge of the colony was flat while the cell is oval and hyaline and it reproduces by single cell budding. The yeast cell formed faint capsules. There was no finding of any ascospore. There was no finding of existing true hyphae nor pseudohyphae. The laboratory test, all the yeast of Rhodotorula sp. isolates were effective in inhibiting the anthracnose disease which was to reduce the diameter of anthracnose spot. The inhibition effectiveness was ranging around $35-73 \%$ on the bruised chili fruit condition. The Rhodotorula sp. during the field test was effective in controlling the anthracnose disease caused by Colletoreichum acutatum fungi. The effectiveness was shown by the reduction of the visible intensity of the disease. The controlling effectiveness reached 97\%.
\end{abstract}

Keywords: Anthracnose, Chili, Biological control, Rhodotorula sp.

\section{INTRODUCTION}

One of the obstacles in the cultivation of chili plants is the attack of the pathogen Colletotrichum acutatum cause of anthracnose disease [1]. The disease attacks in the period in the field and post-harvest. The main attack of anthracnose disease pathogens is the economic value of plants that is on the fruit. This disease results in great decrease of the fruit quality because the fruit becomes rotten and unfit for consumption. The implementation of Integrated Pest Management in pest control has become government policy, where the use of pesticide is the last alternative. To reduce the use of pesticides, it is necessary to find alternative pest control environmentally friendly. Currently, attention is beginning to shift to biological resources in improving plant health, through the role of beneficial microbial phyllosphere and fructosphere.

Microbes are beneficial as biological control agents or resistivity inducers, living in the phyllosphere, fructosphere, and rhizosphere. Currently, beneficial microbes in increasing plant resistance/health are studied as the yeast and yeast like fungi groups as inhibitors of pathogenic growth that affect plant particles or as bioprotectants. Some fructoplane yeasts are biological control agents that can potentially suppress pathogens that attack fruit in the field. Such fructoplane yeasts are Rhodotorula sp., Candida sp., Debaryomyces sp, and others.

The objective of this study was to determine the ability of the yeasts of Rhodotorula sp. to inhibit the infection and the development of anthracnose disease in large chili plants in the laboratory and in the field.

\section{METHODS}

The study used an experimental method with a complete randomized simple design for laboratory research and randomized block design for field research. Laboratory experiments consisted of eight treatments: without yeast application, Rhodotorula isolate 1, Rhodotorula isolate 2, Rhodotorula isolate 3, Rhodotorula isolate 4, Rhodotorula isolate 5, Rhodotorula isolate 6, and Rhodotorula isolate 7. Isolate Rhodotorula sp. with high inhibitory power then used for field testing. Field trials consisted of 3 treatments, namely: application of Rhodotorula sp. only, Rhodotorula sp. + anthracnose pathogens, and pathogens only (C. acutatum). Yeast isolates were applied 3 times (concentration $1,8 \times 10^{8}$ cell $/ \mathrm{ml}$ ), in the fruit formation phase. The test plant used large curly chili species.

\section{A. Isolation of Rhodotorula sp. Yeast}

The yeast was isolated from the healthy chilies grown in the field and came from various locations in Malang. Chili fruit specimens included young fruit, the fruit is old but not yet ripe, and the chili fruit is ripe. Each $20 \mathrm{gr}$ is cut into pieces, placed in an erlenmeyer containing $50 \mathrm{ml}$ sterile distilled water and was shaken. The results of the blow were diluted from $10^{0}$ to $10^{6}$. A total of $0.1 \mathrm{ml}$ of each dilution suspension result was grown sprinkled on MEA medium (Malt Extract Agar). The cultures were incubated at room temperature for three days. The yeast isolates with reddish-red colored colonies were moved to fresh MEA medium. The red yeast isolate was then purified by transferring the colony repeatedly to the medium for the MEA and PDA tilt. Isolates that have been purified were then identified and undergone antagonistic test.

\section{B. Test antagonism in the laboratory}

Large healthy chilies were disinfected with $70 \%$ alcohol and wounded by inserting a sterile needles for $3 \mathrm{~mm}$ deep at about $2 \mathrm{~cm}$ below the base of the fruit. Immediately after the wound, $50 \mu 1$ of yeast cell suspension $\left(10^{8}\right.$ cells $\left./ \mathrm{ml}\right)$ was dropped on the wound. After $60 \mathrm{~min}$ of yeast antagonistic application, $50 \mu 1$ of conidial suspension C. acutatum $\left(10^{7}\right.$ conidia $/ \mathrm{ml}$ ) was dripped on the same wound. Incubated at room temperature inside a damp, enclosed plastic box. Observation of symptoms of the disease was done daily and at day 8 the diameter of anthracnose patches was measured.

\section{Test antagonism in the field}

Chilies are grown on polybags. The yeast antagonists and pathogenic fungi are inoculated by spraying cells or conidium. The yeast isolates were applied at a dose of $50 \mathrm{ml} /$ plant. The 
antagonistic yeast and anthracnose pathogenic fungi were inoculated at the time the pepper plant was fertilized (nine weeks after planting). Spraying yeast was done in the afternoon (at $05.00 \mathrm{pm}$ ) and in the next day it underwent the pathogen conidia spray by the same time as yesterday. After inoculation/spraying the plant is closed for 48 hours with clear plastic hoods to keep the air humidity around the test plant. Observations made are the incubation period of disease and disease intensity.

\section{RESULTS AND DISCUSSION}

\section{A. Isolation and Identification of Red Yeast Rhodotorula sp.}

The isolation activity of fructoplane yeast from red chilies was obtained by six isolates of yeast Rhodotorula. The pure white culture of Rhodotorula was developed from a single colony on the exploration of the pour plate method. Generally obtained by a type of yeast that is more diverse and higher population of fruktosfer chilies that are not exposed to toxic compounds than fruktosfer environment that has been exposed to toxic compounds. Toxic compounds are mainly derived from the spraying of insecticides, akarisida, fungicides or other pesticides. The characteristics of the yeast Rhodotorula media extract yeast peptone glucose agar (GPY) was a colony of pink, red, coral, and yellow. The colony looked soft with a smooth surface. The edges of the colonies were flat. Microscopic observation leavened with microscope magnification of 400X, Rhodotorula yeast cells were oval and hyaline, reproduce vegetatively by budding cells singly. The yeast cells formed a faint capsule. No ascospores were found. There was no true hyphae or pseudohypha.

Note yeast Rhodotorula has a fast growth average, cook within five days. Colony morphology is pink to coral, but often orange, red or yellow colonies. Colonies are yeast-like, soft and smooth. Rhodotorula yeast grown on cornmeal mediumtween 80 to be at a temperature of $25^{\circ} \mathrm{C}$ for 72 hours, stem cells are round or oval, sometimes seem a little pseudohyphae rudimentary. No ascospores are found. Dampened capsules are sometimes formed. The yeast Rhodotorula did not breed vegetatively by cell division [2]. The genera of Rhodotorula positive hydrolyzes urea.

\section{B. Test of Rhodotorula Isolate Antagonism at Laboratory}

Place treatment of chili pepper with the wound resulted in early symptoms of anthracnose disease in the control treatment appeared on the second day after inoculation. Whereas in the treatment of the isolates of yeast Rhodotorula symptoms of new anthracnose disease appeared on day 5 or 6 after inoculation even though it occurred only in several replication instead of all of them. Inoculation of chili pepper with yeast Rhodotorula causes delay of incubation period for 3 or 4 days. The occurrence of such delays is significant since the incubation period of the pathogen $C$. acutatum ranges from 2-3 days after inoculation of varieties sensitive to anthracnose disease. Chili without wounded by treatment of yeast isolates Rhorotorula did not produce anthracnose disease symptoms until the test was completed (ten days after inoculation). The incubation period is the time interval between inoculation and the appearance of symptoms of the disease. The length of the incubation period is influenced by the specificity of the host pathogen combination, with the host development rate, and with the temperature of the infected plant environment. The success of C. acutatum infection is supported by the presence of the wound. The presence of the wound means the loss of mechanical defenses on the surface of the fruit. The wound that occurs on the fruit surface is like a wide open entrance for a pathogen for penetration.

\section{Anthracnose Spotted Diameter}

The mean of disease diameter due to yeast application is presented in Table 1.

Table 1. Average diameter spot of anthracnose disease on chili fruit due to treatment of yeast kinds rhodotorula sp. (with the wound)

\begin{tabular}{|c|c|c|c|c|}
\hline \multirow[t]{2}{*}{ Treatment } & \multicolumn{2}{|c|}{$\begin{array}{l}\text { Spotting Diameter } \\
\text { (mm) }\end{array}$} & \multicolumn{2}{|c|}{$\begin{array}{c}\text { Effectiveness of } \\
\text { Diseases Inhibition } \\
(\%)\end{array}$} \\
\hline & $4 D A I$ & $8 \mathrm{DAI}$ & $4 D A I$ & $8 D A I$ \\
\hline Control (without yeast) & $5.67 \mathrm{e}$ & $15.50 \mathrm{~d}$ & - & - \\
\hline $\begin{array}{l}\text { Rhodotorula yeast } \\
\text { isolate } 1\end{array}$ & $1.67 \mathrm{bc}$ & $6.17 \mathrm{a}$ & 70.55 & 60.19 \\
\hline $\begin{array}{l}\text { Rhodotorula yeast } \\
\text { isolate } 2\end{array}$ & $0.67 \mathrm{ab}$ & $13.00 \mathrm{~d}$ & 88.18 & 16.13 \\
\hline $\begin{array}{l}\text { Rhodotorula yeast } \\
\text { isolate } 3\end{array}$ & $4.33 \mathrm{~d}$ & $\begin{array}{c}9.67 \\
b\end{array}$ & 23.63 & 37.61 \\
\hline $\begin{array}{l}\text { Rhodotorula yeast } \\
\text { isolate } 4\end{array}$ & $0.00 \mathrm{a}$ & $\begin{array}{c}4.50 \\
\mathrm{a}\end{array}$ & 100.00 & 70.97 \\
\hline $\begin{array}{l}\text { Rhodotorula yeast } \\
\text { isolate } 5\end{array}$ & $1.67 \mathrm{bc}$ & $\begin{array}{c}4.17 \\
\mathrm{a}\end{array}$ & 70.55 & 73.10 \\
\hline $\begin{array}{l}\text { Rhodotorula yeast } \\
\text { isolate } 6\end{array}$ & $2.33 \mathrm{c}$ & $\begin{array}{c}10.00 \\
b c\end{array}$ & 58.91 & 35.48 \\
\hline $\begin{array}{c}\text { Rhodotorula yeast } \\
\text { isolate } 7\end{array}$ & $2.00 \mathrm{c}$ & $\begin{array}{c}4.83 \\
\mathrm{a}\end{array}$ & 64.73 & 68.84 \\
\hline
\end{tabular}

The giving of the isolates of Rhodotorula sp. were able to inhibit the rapid development of anthracnose disease. The results of the average difference test show that red chili fruit treated with seven kinds of isolates Rhodotorula sp. resulting in an average diameter of anthracnose spots smaller and significantly different with control (without yeasts, inoculated, pathogens only). This means the presence of Rhodotorula sp. on the wounded chili is able to suppress and inhibit the speed of chili pepper damage due to infection of $C$. acutatum pathogens. This means that the presence of Rhodotorula sp. yeast effectively inhibits the development of anthracnose diseases. The ability of Rhodotorula sp. To suppress the progression of anthracnose disease is because the yeast is able to prevent colonization and cultivation of $C$. acutatum fungus on the part of the wounded chili that comes later. The presence of Rhodotorula sp. can damage hypha and conidia $C$. acutatum.

The existence of Rhodotorula sp. appears to cause conidia of pitted pathogenic fungi. The conidia can no longer germinate, reducing the number of hyphae that will infect the chili tissue. Under microscope the presence of yeast Rhodotorula sp. primarily causing conidia pathogenic damage in the lysis of conidial wall cells so that the conidia become perforated and can not germinate (conidia pathogens to death). Candida famata yeast and Rhodotorula mucilaginosa were able to suppress $C$. gloeosporioides anthracnose pathogens in papaya [3]. Both yeasts produce hydrolytic enzymes that are responsible for cell wall degradation; increase the number of sterile mycelium; and suppress the diameter of the growth of pathogenic fungi. $R$. mucilaginosa uses parasitism mechanism to control pathogens, while Candida famata parasitism and 
nutritional competition. The yeast colonizes perfectly and forms a cell matrix that captures spores and suppresses spores germination. Hyphae from spores germination pathogen appear under a microscope surrounded by yeast cells. The mechanism of parasitism can be demonstrated through the secretion of antagonistic agent hydrolytic enzymes. For example antagonistic yeast Rhodotorula mucilaginosa has a high hydrolytic enzyme activity, which produces enzymes $\beta$ 1,3-glucanase, nagase and chitinase to inhibit fungi $C$. gloeosporioides.

Chili fruits are wounded and treated with yeasts of Rhodotorula sp. but without inoculation with the fungus $C$. acutatum causes the wound to dry and no symptoms of any illness. Apparently the colonization of yeast Rhodotorula sp. at the site of the wounded on the pepper does not cause cell wall degradation. The interaction between yeasts of Rhodotorula sp. with the cell wall of the host plant does not cause changes in the cell wall structure. This proves that yeast Rhodotorula sp. is not a pathogen in pepper plants. Rhodotorula sp. yeast which is used in this study isolated from the surface of large chili so it is very possible that the yeast is a microorganism of the inhabitants of the surface of chili (indigenous) or epiphytic microflora inhabit the fruit surface. It is likely that the yeast cells of Rhodotorula sp. breeding on the tissue of the wilted pepper and forming a matrix of yeast cells which further closes the cracked fruit tissue due to the wound.

In the tissue of wounded chilies Rhodotorula sp. limiting reproduction, multiplication, and suppression of disease. The tissue of chili peppers inoculated with the pathogenic fungi, untreated Rhodotorula sp., pathogen colonization causes the degradation of the cell wall of the host plant to expand and alter the cellulose arrangement. The hypha near the yeast antagonist indicates more severe cytologic damage, such as the occurrence of swollen cell walls and protoplasmic degeneration. The same results are shown which states that colonization of the wounded area on apples by yeast antagonist Candida saitoana does not cause the degradation of the cell wall of the host (apple) [4]. The cell wall of the host directly in contact with the yeast cells of Candida saitoana and pathogenic hyphae $B$ cinerea or Penicillium expansum is well protected and intensively regulates the cellulose arrangement. Also shown to limit colonization of pathogenic fungi, the yeast of Candida saitoana appears to induce the formation of structural defense responses to the apple tissue. The ability of Candida saitoana prevents the growth and development of necrotrophic pathogens and stimulates the structural defense response used as the basis for its biocontrol activity. Yeasts isolated from the surface of the fruit may be more effective as biological control agents because they have been phenotypically adapted to this niche, thus more effectively colonizing and competing against the space and nutrients on the fruit surface [5].

Still development of anthracnose disease in chili fruit inoculated with yeast Rhodotorula sp. allegedly caused during the study environment conditions arranged according to the incidence of anthracnose pathogen infection, namely on the surface of the fruit chili done the wound. The anthracnose that continued to develop on the inoculated chili with Rhodotorula sp. yeast was apparently due to the designated situation which was appropriate for the anthracnose pathogenic infection by giving wound on the plant surface. This wound causes loss of mechanical defense of the fruit and facilitates the occurrence of anthracnose disease infection. This condition is corroborated by the absence of symptoms of the disease in untreated treatment. Until the test time is completed (10 DAI) of test chili berries studied by Rhodotorula sp. and pathogens show no ill symptoms. The occurrence of plant diseases at least there should be contact and interaction between the three components of sensitive plants, virulent pathogens, and the appropriate environment [6]. If the plant is vulnerable and is at a fragile growth rate, virulent pathogens in abundance and in active state, and favorable environments that assist pathogens (for example temperature, humidity, and surface) then the potential number of diseases is very large. The ability of yeast in suppressing the development of anthracnose disease is suspected because the yeast is indigenous in addition also acts as a competitor of space and nutrition with inoculum $C$. gloeosporioides so as to reduce the number of initial infections [7] [8]. Some yeasts such as Debaryomyces sp exhibit inhibitory activity against Colletotrichum acutatum with a reduction in spotted diameter and apparent anthracnose disease intensity, whose inhibitory activity is best when applied prior to pathogen inoculation or acts as a bioprotectant. The presence of microbial phylloplane provides a role to the magnitude of the incidence of infection by plant pathogens. Plants with a low population of microbial phyllosphere are thought to be more susceptible to pathogen attack. While the plants with complex high population of microbial phyllosphere allegedly can be more resistant or protected from pathogen attack. This is because epiphytic or endophytic phyllosphere microbes provide a natural barrier to pathogen attack. In addition, among these microbes are very likely to act as a competitor or antagonistic to pathogens, so it is beneficial to the plant [9]

Yeast is resistant to extreme environments such as in frozen conditions where water activity falls, many bacteria do not survive, making yeast growth multiply rapidly. Yeast is also life-proof on ingredients containing antibiotics, preservatives, and agent antimicrobial agents [10]. The method of control with microbial antagonists against Colletotrichum sp. aims to reduce some initial infections. The preparation of anthracnose disease biological control is made possible by the presence of a saprophytic microflora population on the surface of the plant, which can act as a competitor of space and nutrition with the inoculum of Colletotrichum sp. which is just coming or inhibits the germination of conidia [11].

\section{Test the Antagonism in the Field}

Symptoms of anthracnose disease with control treatment (given pathogens only) appeared on the twelfth day after inoculation. The yeast application simultaneously with pathogens appeared on average on the nineteenth day and symptoms only appeared on one fruit only. While yeast treatment alone without pathogen inoculation did not show any symptoms of the disease until all the fruits were harvested. Spraying chili plants with yeasts causes the delay of incubation period for seven days. The occurrence of such delays is significant since the incubation period of the $C$. acutatum pathogen ranges from 3-4 days after inoculation of chili varieties sensitive to anthracnose disease. The incubation period is the time interval between inoculation and the appearance of disease symptoms. The length of the incubation period is influenced by the specificity of the host pathogen combination, the host development rate, and the temperature of the infected plant environment. The success of fungal $C$. 
acutatum infection is supported by its ability to penetrate directly through the surface of the intact host plant. This penetration can be done by using a pointed hyphae or a nail infection and apresorium.

Still the occurrence of disease in chili plants sprayed yeast Rhodotorula sp. allegedly caused during the study environment is very supportive for the emergence of anthracnose pathogen infection, which is early inoculation of pathogens, the plant is given transparent plastic shade to maintain the humidity is very important for the occurrence of anthracnose disease infection. It is also thought to be caused by the way the yeast application coincides with the pathogen, causing less effective antagonistic power of yeast in inhibiting pathogen infection; because the yeasts of Rhodotorula sp. still in the adaptation stage have not colonized yet. While the pathogen $C$. acutatum are in virulent condition and environmental conditions are very favorable for infection (very humid due to rain every day).

\section{E. Disease Intensity}

The average intensity of anthracnose disease due to the treatment of yeast spraying of Rhodotorula sp. are presented in Table 2.

Table 2. Average intensity of anthracnose disease (\%) on red chili and effectiveness of control due to treatment of rhodotorula $\mathrm{sp}$. yeast.

\begin{tabular}{l|l|l|l|l}
\hline \multirow{2}{*}{\multicolumn{1}{c}{ Treatment }} & \multicolumn{2}{c|}{$\begin{array}{c}\text { Intensity of } \\
\text { Disease (\%) }\end{array}$} & \multicolumn{2}{c}{$\begin{array}{c}\text { Effectiveness of } \\
\text { Control }\end{array}$} \\
\cline { 2 - 5 } & $\mathbf{1 9 D A I}$ & $\mathbf{2 5}$ DAI & 19 DAI & 25 DAI \\
\hline Rhodotorula sp. yeast & $0,00 \mathrm{a}$ & $0.00 \mathrm{a}$ & & \\
\hline $\begin{array}{l}\text { Rhodotorula } \text { sp. }+ \\
\text { pathogen }\end{array}$ & $0.17 \mathrm{a}$ & $1,00 \mathrm{a}$ & $\begin{array}{l}97.14 \\
\%\end{array}$ & $\begin{array}{l}97.71 \\
\%\end{array}$ \\
\hline Pathogen (C. acutatum) & $5.94 \mathrm{~b}$ & $43.61 \mathrm{~b}$ & & \\
\hline
\end{tabular}

Note: Number accompanied by the same letter in the same column showed no significant difference in Duncan Test $5 \%$ level. DAI = day after inoculation. For statistical analysis each number is transformed into $\sqrt{(x+0.5)}$.

The treatment of Rhodotorula sp. is significantly different from another treatment. This means by spraying Rhodotorula sp. yeast can suppress the intensity of anthracnose disease. Effectiveness of control with application of Rhodotorula sp. reached $97 \%$ both on observations of 19 DAI and 25 DAI. Rhodotorula $s p$. showed inhibitory activity against $C$. acutatum with reduced diameter of the spots and the apparent intensity of disease attacks. Its inhibitory activity is particularly evident in the destruction of pathogenic fungal hypha and conidia thus reducing initial infection. Damage in the form of hypha cell wall lysis so that under the microscope hypha of pathogen visible pitted. According to Patino-Vera et al. yeasts Rhodotorula minuta is a new antagonistic microorganism against the pathogen Colletotrichum spp. The yeast suspension is applied to mango crops in mango gardens to reduce the intensity of anthracnose disease in mango fruit and the results are the same or better than chemical fungicide applications [12].

The ability of the yeasts of Rhodotorula sp. inhibit the progression of anthracnose disease in the field testing is suspected that the yeast has adapted extensively to a number of varieties of chili plants as endosymbion or endophytic and epiphytic microorganisms. One of the advantages of epiphytic microbes on the plant surface is as a barrier and destroyer of newly arrived pathogens. When as endosymbion the existence of yeasts Rhodotorula sp. is suspected can help the plant meet the needs of its essential nutrients lacking in the environment [13]. Some literature mentions the yeast Rhodotorula sp. produces levanase enzymes, lipases, lipids, and natural pigments. The natural pigments produced are carotenoids [14] [15] [16]. Carotenoids are beneficial to increase the immune system and reduce the risk of degenerative diseases such as cancer, cardiovascular disease, aging, and cataracts. Carotenoids also serve as provitamin A and antioxidants. Rhodotorula glutinis produce a typical carotenoid that is torulene, torularhodin, and $\beta$-carotene in various percentages. Rhodotorula is also rich in lipids, proteins, and vitamins. This makes Rhodotorula the right additional food [15]. Seeing so many of the benefits of yeast Rhodotorula is not impossible that the application of yeast to chili plants has a double benefit, namely as antitremic controlling antagonizing agents as well as producing antioxidant-rich chili fruit that is beneficial to improve human health. Yeast is not dead by the presence of antibiotics and some yeasts have antimicrobial properties that can inhibit the growth of bacteria, fungi, and molds. The existence of resistant properties in a stressful environment then in competition with other microbes yeast more able to live normally [17].

Biological control of diseases of fruits and vegetables with yeast is a promising alternative. The advantages of using yeast as a biocontrol agent include yeast growing fast, tolerant to dry environments, not producing mycotoxins and spores that cause allergies. Some yeasts can live in extreme conditions, for example there is nitrogen in the atmosphere, low or high temperature, hot sunlight, $\mathrm{x}$ rays and ultra violet [18].

\section{CONCLUSION}

Anthracnose disease in chili caused by pathogenic fungus C. acutatum is effectively controlled by Rhodotorula sp. The potential for high control effectiveness is obtained when simultaneously using anthracnose-resistant chili varieties (curly large chili).

\section{ACKNOWLEDGMENT}

I thank to University of Muhammadiyah Malang for supporting this paper through DPPM grant.

\section{REFERENCES}

[1] N. Nantawanit, A. Chanchaichaovivat, B. Panitipan and F Ruenwongsa, "Induction of Defense Response Against Colletotrichur Capsici in Chili Fruit by The Yeast Pichia Guilliermondii Strain R13, Biological Control, vol. 52, no. 2, pp. 145-152, 2010.

[2] C. Kurtzman, J.W.Fell and T.Boekhout, The Yeast: A Taxonomi Study. 4rd, Amsterdam: Elsevier, 2011.

[3] A. Magallon, L. S.G., R. S.J.A and C. S.M., "Parasitism and Substrat Competitions Effect of Antagonistic Yeasts for Biocontrol o Colletotricum gleosporiodes in Papaya (Carica papaya L.)," Mexica J.of Sci. R.1, vol. 1, no. 1, pp. 2-9, 2012.

[4] K. Wilson, N. Glithero, Q.Ma, P.Alspach and M.Walter, "Yea Isollates to Inhibited Blue Mould and Bitter Rot of Apple," Ner Zealand Plant Protection, vol. 59, pp. 86-91, 2006.

[5] R. McLaughlin, W. M.E. and E. Chalutz, "Effect of Inoculur Concentration and Salt Solutions on Biological Control of Postharves Diseases of Apples with Candida sp.," Phytopathology, vol. 80, pp. 456 $461,2000$. 
[6] K. Broders, Characteriza of Colletotrichum Isolates from Apple in Ner Hampshire, University of New Hampshire, 2012.

[7] D. Indratmi, "Use Yeast Fructoplane Debaryomyces sp. For Biologica Control of Colletotrichum gloeosporioides on Chili," Tropika, vol. Vo. 8 No.2, 2000.

[8] I. D, "Potential of Yeast Like-fungi Schizosaccharomyces sp. fo Biocontrol Colletotrichum gloesporioides on Chili Plant," Tropika, vo 10 No. 2, 2002

[9] [. D, "Exploration and Identification of Antagonist Fungus Against C gloeosporioides from Chili Plant Phyllosphere.," Tropika, vol. 9 No.1 2001.

[10] U. Breuer and H. Harms, "Yeast," Yeast, vol. 23, pp. 415-437, 2006.

[11] H. Basha, V. Hemannavar, B. Ramanujam, R. Rangeshwaran and S. Sriram, "Screening of Chilli Microflora and Other Biocontrol Agents for Their Antagonistic Effects on Colletotrichum spp. Infecting Chillies," The J. of Plant Protect. Sci, vol. 2(1), p. 38044, 2010.

[12] M. Patino-vera, B. Jimenez, K. Balderas, M. Ortiz, R. Allende, A. Carillo and E. Gallindo, "Pilot-scale Production and Liquid Formulation of Rhodotorula minuta a Potencial biocontrol Agent of Mango Anthracnose," J. Appl Microbiol, vol. 99, no. 3, pp. 540-550, 2005.
[13] J. Gholamnejad, H.R. Etebarian and N. Sahebani, "Biological Control of Apple Blue Mold With Candida Membranifaciens and Rhodotorula Mucilaginosa. African Journal of Food Science," vol. 4, no. 1, pp. 001-007, 2010.

[14] O. Ariyanti, E. Anwar and D. Kusmana, Potential of Lipid From Rhodotorula sp. for Colesterol Decrease, Competitive Grant Research, 2007.

[15] Heriyanto and L. Limantara, "Carotenoid Production by Rhodotorula sp. Yeast," Eksplanasi, vol. 4, no. 7, 2009.

[16] E. Centre, Microbes in Application, Kalvani University, 2008.

[17] F. Fard, H.R. Etebarian and N. Sahebani, "Biological Control Of Gray Mold Of Apple By Candida membranifaciens, Rhodotorula mucilaginosa and Pichia guilliermondii," Iran. J. Plant Path, vol. 48, no. 1, pp. 17-26, 2012.

[18] C. Gostincar, R.A. Ohm, T. Kogej, S. Sonjak, M.Turk, J.Zajc, P. Zalar, M. Grube, J. H. H. Sun, A. Sharma, J. Chiniquy, C.Y. Ngan, A. Lipzen, K. Barry, Grigoriev IV and N.G. Cimerman, Genome Biotecgnological Potential, Stress Tolerance, and Description of new Spesies, BMC Genomics, 2014. 